\title{
Terapia Cognitiva-Comportamental: da teoria a prática
}

\author{
Beck, J. S. (2013). Terapia Cognitiva-Comportamental: teoria e prática. $2^{a}$ Ed. Porto Alegre. Artmed. 413 p.
}

O modelo psicoterápico baseado em evidências fundamenta-se na teoria cognitivo-comportamental. Essa abordagem agrupa a teoria da personalidade e a teoria da psicopatologia. Além disso, necessita dos conhecimentos técnicos relacionados aos princípios básicos da terapia cognitiva e, da realização de pesquisas na área clínica. Sabendo da necessidade de um material de consulta que proporcione uma visão ampla e atualizada sobre a teoria e a prática, Judite S. Beck preparou o livro-texto Terapia Cognitivo-Comportamental: teoria e prática.

A obra trata dos aspectos fundamentais, explica detalhadamente a teoria a partir de um transtorno do pensamento - o pensamento disfuncional - e de como este reflete na forma do paciente interpretar determinada experiência, principalmente nos transtornos psiquiátricos e a sua prática clínica na busca de explicações mais prováveis, assinalando essas interpretações tendenciosas e propondo alternativas, ou seja, treinando as habilidades cognitivas. A obra é fruto de 25 anos de estudos, pesquisas empíricas e realização de workshops e treinamentos realizados pela autora. Composto de 21 capítulos e três apêndices.

No primeiro capítulo, Introdução à Terapia Cognitivo-Comportamental, a autora responde a cinco perguntas, quais sejam, o que é terapia cognitivo-comportamental, como ela foi desenvolvida, o que as pesquisas dizem sobre sua eficácia, quais os seus princípios básicos e como tornar um terapeuta cognitivo-comportamental eficaz. Visão geral do tratamento é o título do Capítulo 2. O texto apresenta informações sobre o desvendar a relação terapêutica, desenvolver a confiança e rapport com o paciente desde o primeiro contato; o terapeuta age como uma equipe e busca feedback por meio das reações emocionais do paciente e, de forma verbal, no final de cada sessão.

A Conceituação cognitiva é o tema do próximo capítulo. O modelo cognitivo parte da hipótese de que as emoções, os comportamentos e a fisiologia de uma pessoa são influenciados pela própria percepção dos eventos; assim, a interpretação de uma situação pode levar a pensamentos automáticos que geram uma reação. Já o quarto capítulo, Sessão de avaliação, apresenta os objetivos e a estrutura de uma sessão de avaliação, ou seja, como realizar uma avaliação e relatar o diagnóstico provisório, assim como os objetivos iniciais do tratamento e as expectativas do paciente em relação ao mesmo. Para tanto, usam-se desde relatórios médicos a informações de parentes e amigos.

Estruturar a primeira sessão, tema do quinto capítulo, informa como discutir com o paciente o seu diagnóstico, verificar o humor, definir objetivos, começar a trabalhar em um problema, definir exercício para casa e solicitar feedback. Educar o paciente sobre o modelo cognitivo na primeira sessão ajuda-o a entender como os seus pensamentos afetam suas reações. No Capítulo 6, Ativação comportamental, o intuito é planejar as atividades que oferecem um sentimento de realização ou prazer, além de melhorar o humor e o comportamento. Nesse sentido, o paciente se torna mais ativo e desenvolve a autoeficácia.

A Sessão 2 e posteriores: estrutura e formato são os elementos do sétimo capítulo. A sessão é dividida em três partes, a saber, inicial, intermediária e final. A autora detalha sobre os itens e fecha o capítulo com uma figura que informa as anotações da terapia em que descreve a estrutura e o formato de uma sessão. No capítulo seguinte sobre os Problemas na estruturação da sessão, perguntas como: você conseguiu interromper o paciente para direcionar a sessão, familiarizar o paciente sobre o tratamento, conseguir a adesão do paciente, estabelecer uma aliança terapêutica são respondidas com exemplos de um caso clínico.

Nesse modelo cognitivo a explanação de uma situação expressa os pensamentos automáticos e influencia a emoção, o comportamento e a resposta fisiológica, portanto, Identificando pensamentos automáticos é o conteúdo do nono capítulo. As características dos pensamentos são um fluxo de pensamentos que coexiste com um fluxo de pensamentos mais manifesto. Identificando emocões, tópico do décimo capítulo, apresenta um dos principais objetivos do tratamento, que é o alívio dos sintomas. O fundamental é diferenciar pensamentos automáticos de emoções, distinguir as emoções e nomeá-las e, após, classificar sua intensidade.

Avaliando os pensamentos automáticos é o próximo tema abordado no livro, Capítulo 11. Ao detectar um pensamento automático, o terapeuta deve conceituar se esse pensamento é importante para se focar, se ele é disfuncional ou recorrente. Nesse momento, o objetivo 
é ajudar o paciente a pensar em resultados mais realistas. No capítulo 12, a autora aborda Respondendo aos pensamentos automático. A avaliação do paciente e a resposta aos seus pensamentos entre as sessões é admitir que o paciente vivencie dois tipos de pensamento fora da sessão, quais sejam, os que ele já identificou e avaliou na sessão e as cognições novas. Para tanto, utiliza-se de técnicas.

O Capítulo 13 discorre sobre Identificando $e$ modificando crenças intermediárias. As ideias ou entendimentos mais profundos geralmente são articulações que o paciente tem a respeito de si, dos outros e de seu mundo pessoal. Para isso utiliza o Diagrama de Conceituação Cognitiva e compartilha verbalmente com o paciente. Identificando e modificando crenças nucleares é o título do próximo capítulo. Nesse, o intuito é aprofundar as ideias mais centrais que a pessoa tem de si. Suas crenças nucleares negativas, que podem ser associadas ao desamparo, desamor e desvalor. Outras técnicas cognitivas e comportamentais, tema do capítulo 15 , tem como finalidade influenciar o pensamento, o comportamento, o humor e a estimulação fisiológica. Nesse tópico são detalhadas várias técnicas.

No Capítulo 16, o Imaginário é discutido. A falha em identificar e responder a imagens perturbadoras poderá resultar em sofrimento para o paciente, portanto, normalizar e ensiná-lo a respeito das imagens ajuda a reduzir a ansiedade e aumenta a probabilidade de obter controle sobre sua angústia. Exercícios de casa é o foco do Capítulo 17. Esses exercícios são parte integrante da terapia cognitivo-comportamental, pois ampliam as oportunidades de mudança cognitiva e comportamental durante toda a semana do paciente e facilita a remissão do transtorno, além de ensinar-lhe habilidades que possa usar ao longo de sua vida.

Oferecer a oportunidade de testar e fortalecer as suas habilidades é tema do Capítulo 18, intitulado de Término e prevenção de recaída. Após a redução nos sintomas e a aprendizagem das habilidades básicas, pode-se combinar a redução da terapia gradativamente, programando sessões de reforço em aproximadamente 3, 6 e 12 meses após o término. Tomar decisões e planejar o tratamento é o tema do Capítulo 19, intitulado de Planejamento do tratamento. Para manter a terapia focada e na direção certa precisa perguntar continuamente qual é o problema específico aqui e o que estou tentando atingir.

Os Problemas na terapia são discutidos no Capítulo 20. Mesmo os terapeutas mais experientes encontram dificuldades em estabelecer uma aliança terapêutica, conceituar as dificuldades corretamente e trabalhar de forma coerente em direção aos objetivos. Além disso, essas dificuldades aprimoram as habilidades, flexibilidade e criatividade do terapeuta. Evoluindo como terapeuta cognitivo comportamental é o último capítulo da obra. Trata-se de lembretes que descrevem resumidamente os passos para dar início à prática da terapia cognitivo-comportamental. A seguir, a autora aponta 15 itens, habilidades pessoais e profissionais, para se tornar proficiente em terapia.

Para finalizar a obra, a autora apresenta três apêndices, sendo um com o relato de caso, outro com recursos da terapia cognitivo-comportamental e o último a Escala de Avaliação da Terapia Cognitiva. Resumindo, trata-se de um manual que apresenta a fundamentação teórica e a sua prática clínica com vinhetas e sugestões técnicas de atuação da terapia cognitivo-comportamental. A leitura torna-se agradável e interessante pela linguagem simples, acessível e de encadeamento objetivo e instigante. Considera-se que a publicação desse livro-texto, visto como uma guia, permite uma ampla visão a respeito dos conceitos e aplicação da técnica terapêutica, apresentando uma compreensão global das peculiaridades do trabalho na abordagem, portanto, uma leitura essencial para iniciantes e profissionais habilitados para atuar de forma eficiente e eficaz.

Sobre a autora:

Marlene Alves da Silva é pós-doutoranda da Universidade do Minho - Braga - Portugal, doutora e mestre em Psicologia com ênfase em Avaliação Psicológica, coordenadora e professora de curso de especialização com chancela da Faculdade Guanambi e psicóloga na clínica Fênix, credenciada pelo DETRAN.

\section{Contato com a autora:}

Contato: Av. Otávio Santos, 261 sala 8, Vitória da Conquista- BA 45020-750.

E-mail: profa.marlenesilva@gmail.com 